MAURICIO BEUCHOT

\title{
Semiótica y filosofía de la conciencia: conductismo y mentalismo en la filosofía del lenguaje
}

\section{Introducción}

D ONER en tela de juicio a la conciencia suena bastante excén1 trico y hasta contradictorio. Pues el problema de su existencia resulta ser de los que se resuelven por la reducción al absurdo, del tipo de los que inmortalizó Aristóteles en su Protréptico: para poner en tela de juicio a la conciencia es necesario tener conciencia.

Pero no es su existencia lo que se problematiza sin más, sino el fundamento y la metodología de nuestro discurso, y nuestra teoría sobre ella. El propio Skinner, considerado como negador de la conciencia, al hablar de las críticas injustificadas que se han hecho al conductismo, pone como la más infundada la acusación de que "ignora la conciencia, los sentimientos y los estados de la mente". 'Se trata, pues, de ajustar lo mejor posible a ese hecho que es la conciencia nuestro discurso racional sobre ella.

Y esto tiene sus dificultades. La primera de ella es: ¿cuál es la lógica de nuestro discurso sobre la conciencia? Pero esto sólo se encabalga en otras dos cuestiones más de fondo: ¿qué significamos al hablar de la conciencia? y ¿qué realidad ontológica tiene nuestra conciencia? Preguntas que, a su vez, dependerán de otra: ¿cuál es nuestro acceso cognoscitivo a la conciencia? Como se ve, se conjuntan los planos sintáctico, semántico y pragmático, los cuales configuran la estructura

1 B. F. Skinner, thout Behaviorism, New York: Vintage Books. 1976. p. 4. 
semiótica con la que se ha de abordar el problema. A esto se añaden la instancia epistemológica y la instancia ontológica.

El aspecto sintáctico representa la investigación de la expresión lógica de nuestro discurso acerca de la conciencia. El aspecto semántico constituye ìa inquisición de la referencia que asignamos a dicho discurso, a saber, qué es lo que consideramos como referente o referentes del mismo. El aspecto pragmático consiste en esclarecer los modos principales como hablamos de la conciencia a través de su uso en nuestro contexto psicológico-social. A estos dos últimos aspectos se vincula el ontológico, y éste exige, en último término, una justificación epistemológica (el método y el criterio para llegar a conocer lo que decimos de la conciencia).

Entendemos la semiótica y sus partes según los lineamientos generales de $\mathrm{Ch}$. Morris; ella nos servirá para abordar la parte más filosófica configurada por la ontología y la epistemología. Procederemos, pues, en este trabajo, a aplicar a algunas expresiones principales sobre la conciencia los correspondientes análisis sintáctico, semántico y pragmático para aplicar luego a sus resultados los análisis ontológico y epistemológico. Preferimos, en cuanto a esto último, hablar primero de ontología y después de epistemología, no por invertir el orden acostumbrado, sino porque las razones epistemológicas que aduzcamos servirán para confirmar lo que hayamos enunciado como el status ontológico de la conciencia.

\section{Sintaxis: la lógica del discurso sobre la conciencia}

Consideremos las expresiones siguientes:

1. Yo me doy cuenta de que tengo en este momento una conclusión importante.

2. Yo me doy cuenta de que tengo en este momento una sensación visual de un objeto triangular y verde.

3. Yo me doy cuenta de que tengo en este momento una gran alegría.

4. Yo me doy cuenta de que quiero algo difícil.

En las expresiones mencionadas, que tratan de abarcar los sectores principales de nuestra actividad consciente (cognoscitiva racional, cognoscitiva sensorial, emotiva y volitiva), 
notamos que se habla de un percatarnos de algo, con una seguridad casi presuntuosa.

Esta afirmación de percatarnos de algo con certeza haría a Wittgenstein aconsejarnos una mayor reserva, y, de acuerdo a sus reflexiones sobre la certeza, nos sugeriría preferir expresiones más modestas, como el "me parece que me doy cuenta de que..." o "creo que me doy cuenta de que..."

Tal vez consideraciones semejantes han hecho a algunos pensadores incluir este tipo de expresiones sobre la conciencia entre las expresiones u oraciones de creencia. Pero, aun formulándolas como oraciones de creencia, las oraciones acerca de la conciencia manifiestan tener consistencia lógico-sintáctica. No hace falta abundar en apologías para demostrarlo.

Nos̀ basta, para hacer ver que a nivel sintáctico las oraciones sobre la conciencia son consistentes, referirnos a la legitimación que de las mismas ha hecho Héctor-Neri Castañeda, quien, aprovechando y corrigiendo el sistema de oraciones de creencia de Jaako Hintikka, lo aplica a las oraciones de conciencia. A pesar de las dificultades que tales oraciones encierran, ha sabido superarlas, y ofrece un buen camino para superar las dificultades que siguen presentándose.

Expuesto de modo sumamente esquemático, el camino es el siguiente. Castañeda procede, por así decir, desde el exterior de la conciencia, pasa a su interior, sale de nuevo y regresa a ella. como en espiral. Y todo en un nivel de expresión. Primero atiende a las expresiones de conciencia como referidas a otro, en tercera persona. ${ }^{3}$ En seguida intenta colocarlas en el propio sujeto, como una tercera persona que sabe, sin embargo, que es la propia ${ }^{4}$ Después aplica ese autoconocimiento, a través de una ilación, a las otras personas, concediendo que también ellas poseen ese autoconocimiento. ${ }^{5} \mathrm{Y}$ regresa al propio sujeto, para recuperarlo en su mismidad. ${ }^{\circ}$ Se muestra, así, como una

: Cir. 1. Wittgenstem. Loher Geniss/ncit. Franckfurt am Main: Suhrkap Verlag. 1970. núm. $8 . \mathrm{pp} .10-11$.

"Cir. H. N. Castaneda." He: A Study in the logic of Self-Conciousness". en Ratio. 7 (1966). pp. 130-157.

+ Cfr. Klem. "On the logic of Self-Knowledge". en loths. I (1967), pp. 9-21.

s Cfr. Ielem. "On the Logic of Attributions of Self-Knowledge to Others". en The Journal of Philosophr. 65 (1968). pp. 439-456.

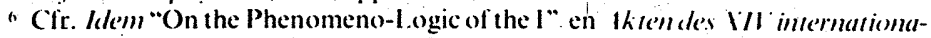
len Kongresses für Philosophie, Univ. of Vienna. 1969. vol. III. pp. 260-266. 
fluctuación de la conciencia entre las expresiones con el pronombre "él" y las expresiones con el pronombre "yo". En cualquier caso, nos parece lo más plausible que el pronombre que predomine debe ser el de primera persona; pues, aunque el autoconocimiento se exprese como referido a otro, en última instancia debe reducirse al que tiene como referencia al propio sujeto.

La necesidad de introducir el "yo" en los esquemas lógicos es necesario para dar consistencia al discurso referido a la conciencia. Veamos algo sobre la fundamentación sintáctica de la lógica del "yo" o pronombre personal en primera persona.

En el caso de la construcción sintáctica, encontramos que es un elemento del tipo llamado "indicador", esto es, la clase de expresiones que comprende pronombres personales y demostrativos, adjetivos y verbos usados para hacer una referencia demostrativa. El indicador "yo" es el más importante de los indicadores, y aún más que todos los nombres y descripciones. Este elemento indicador que es el pronombre personal en primera persona tiene su construcción sintáctica correcta en oraciones como "Yo existo ahora". Guardando esta corrección sintáctica no puede dejar de referirse al objeto que intenta referirse. De su corrección sintáctica podemos pasar a su corrección semántica.

\section{Semántica la referencia del discurso sobre la conciencia}

La corrección sintáctica y semántica de las oraciones con el pronombre "yo" quedan garantizadas a través del hecho siguiente. En el caso de las formas sintáctica y semántica, decir "Yo no existo ahora" es autocontradictorio, es internamente inconsistente, es una contradicción sintáctico-semántica. Es parecida a la que ocurriría si digo ahora: "Yo no estoy expresando algo en este momento", lo cual se ve falsificado por el hecho de mi acto de expresión. Sobre esto observa Castañeda:

La razón de que muchos filósofos no hayan visto la inconsistencia interna de enunciados negativos tales como "Yo no existo ahora" es que "Yo soy H.N. Castañeda" y "H.N. Castañeda no existe ahora" son ambos enunciados contingentes. Pero, por supuesto, 
la contingencia de los dos últimos enunciados no establece la contingencia del primero. (...) Claramente, la proposición "Yo existo", aseverable por mí, es diferente de la proposición "H.N. Castañeda existe". ${ }^{7}$

A esta observación de Castañeda sobre la diversidad de tales enunciados, que me parece acertada, quisiera añadir algo que me parece fundamental. Ciertamente la proposición "Yo existo ahora" no tiene la contingencia de las otras; pero lo que no llega a ver Castañeda, y que debe añadirse, es que tal enunciado no es contingente porque el nexo que representa no es ún nexo lógico contingente, sino un nexo lógico necesario. Un nexo necesario existencial que, si bien no tiene la fuerza del nexo necesario esencial que se da en una proposición analítica, es, sin embargo, necesario; de modo que puede hablarse de una clase especial de tautología referencial. ${ }^{8}$

La prioridad, en este caso, de la primera persona sobre cualquier paráfrasis en tercera persona se ve de la siguiente forma. El correspondiente del indicador "yo" no puede ser el indicador "él". Más bien la expresión equivalente es la que Castañeda llama un cuasi-indicador, que simboliza como "él*". Con éste tenemos una proposición cuasi-indexical. Tomemos el ejemplo utilizado por Castañeda:

1. El Editor de Soul cree (en el tiempo $t$ ) que él (mismo) es un millonario.

De acuerdo con lo que se ha dicho, el Editor de Soul tiene una creencia cuyo objeto es la proposición expresada en la cláusula que va en oratio obliqua: "él (mismo) es un millonario". Esa proposición es tal que el Editor podría haberla expresado en $t$ aseverando:

2. Yo soy un millonario.

Así pues, la única paráfrasis equivalente a la oración (2) de primera persona es la oración (1) en tercera persona; pero el pronombre que ahí figura no es otro indicador, como "yo", sino un cuasi-indicador, "él*". Que no se puede sustituir "yo" por otro indicador de tercera persona se ve por esto:

El pronombre "él (mismo)" en (1) tiene un papel especial:

7 Ihicl. p. 261.

" Sobre estas tautologías referenciales, cfr. D. Pears. "ls Existence a Predicate?", en P. F. Strawson (ed.), Philosophical Logic. Oxford: University Press. 1967. 
i) no se usa para hacer una referencia demostrativa, ii) se refiere al Editor de Soul indirectamente, iii) aparece como oratio obliqua, y iv) se usa para atribuir referencia de primera persona al Editor de Soul, aún sea implícitamente. Por todo ello es más bien un cuasi-indicador, "él*", como se ha dicho. Este cuasi-indicador tiene las siguientes propiedades peculiares que señala Castañeda:

a) No puede ser sustituido por su antecedente salva propositione. Es decir, la proposición (1) no es equivalente a "El Editor de Soul cree en el tiempo $t$ que el Editor de Soul es un millonario". 9 Porque puede darse el caso de que esa persona no crea ser el Editor de Soul, por pensar que no es efectivo aún su nombramiento, sino que acaba de ser elegido sin entrar todavía en funciones.

Si pretendemos sustituir "El Editor de Soul" por otra descripción, como "El único que es $\Phi$ ", donde no figura "él*", de todas maneras la proposición (l) es diferente de la proposición correspondiente "El único que es $\Phi$ es un millonario". Porque se puede dar el caso de que dicho Editor no crea que es el único que es $\Phi$.

Si pretendemos sustituir "El Editor de Soul" por un nombre propio lógico, como $A$, de todas maneras la proposición (1) es diferente de la proposición correspondiente " $A$ es un millonario". Porque también se puede dar el caso de que dicho Editor no crea que él es $A$.

b) Tampoco "él" puede ser sustituido en (1), salva propositione, por otro indicador que se refiera al Editor de Soul. La razón es que la referencia indexical que tendría ese otro indicador no tendría el alcance que debe tener en la oración donde figura. Por ejemplo, si se sustituyera por el indicador "él"(no por el cuasi-indicador "él*") en "El (este hombre) es un millonario", podríamos analizarla como: "Hay una propiedad $\Phi$-idad tal que él [indexical] = el único que es $\Phi$ y el Editor de Soulcree en el tiempo $t$ que el único que es $\Phi$ es un millonario".

Pero este análisis nos muestra que el indicador "él" entra sólo aparentemente en el alcance de "cree", es decir, que está fuera de la propositio obliqua y tiene como alcance la propo-

${ }^{9}$ H. N. Castañeda. "On the Phenomeno-Logic of the I", p. 261. 
sición completa. Con lo cual no tiene ya el alcance que le es debido. Estos análisis llevan a Castañeda a la siguiente conclusión:

Por consiguiente, la proposición de primera persona singular (2) es diferente de cualquier otra proposición de tercera persona en oratio recta. De manera patente, las mismas consideraciones valen para toda otra proposición de primera persona. Así, de modo más general, ninguna proposición de primera persona es idéntica a ninguna otra proposición de tercera persona, si ambas están en oratio recta. ${ }^{10}$

Con esto se garantiza que la proposición de primera persona no es reductible a ninguna de tercera persona. La primera persona, pues, tiene su propia lógica.

Pragmática: el uso del discurso sobre la conciencia

Lo que intentan las oraciones de conciencia es aludir al conocimiento directo de un concepto individual de la propia persona. Definamos así el conocimiento directo: "s está familiarizado con $x$ en $\mathrm{t}=\mathrm{df}$. Hay un $p$ tal que $i$ ) $p$ es auto-presente para s en $\mathrm{t}$ y $i i)$ hay una propiedad que $p$ implica que $x$ la tiene". Y el concepto individual así: "s tiene un concepto individual $=\mathrm{df}$. Hay una proposición $p$ y un concepto individual c tales que $i$ ) $p$ implica que $x$ tiene c y ii) $p$ es conocida por s". De estas definiciones, Roderick Chisholm obtiene:

Podemos decir que si una persona está directamente familiarizada con ella misma, entonces tiene un concepto individual de sí misma. Pues si está directamente familiarizada con ella misma, entonces hay un estado de cosas que es auto-presente para ella; este estado de cosas implicará que la persona tiene cierto concepto individual; y puesto que el estado de cosas es cierto para ella también será uno que ella conoce."

Entonces, cuando utilizo una expresión de conciencia

10 Ihid, p. 263.

" R. Chisholm, Person and Object. A.Metaphısical Stud1, London: George Allen and Unwin. 1976, p. 30. 
como "yo me siento deprimido" o "yo veo una figura triangular y verde", estoy directamente familiarizado conmigo; pues tales proposiciones son auto-presentes e implican que yo tengo una propiedad. Implican un concepto individual, el de ser yo, o ser idéntico conmigo mismo, y una propiedad que le conviene. $\mathrm{Y}$, ya que tal proposición es auto-presente, es conocida por mí como siendo verdadera.

\section{Ontología: la conciencia como función}

Tomando el término "función" en sentido corriente, podemos decir que el status ontológico de la conciencia es ser una función de la inteligencia. La inteligencia conoce los distintos actos y objetos de la persona, y con ello le da un conocimiento de sí misma. Al hacer esto, la inteligencia es inteligencia consciente, es decir, se ejercita como conciencia.

\section{Epistemología: la introspeción como camino hacia la conciencia}

¿Sobre la base de qué evidencia empírica se postulan las entidades mentales de la conciencia? Aquí tocamos el espinoso y radical problema de una experiencia interior o introspección. La.validez de la introspección es una premisa fundamental del mentalismo. Por lo cual, no la podemos introducir precipitadamente. Si se acepta como auténtica experiencia, hace que la postulación de entidades mentales no sea tan sólo un enunciado teórico o inferido, sino un enunciado empírico con toda su fuerza. Pues bien, ise da esa experiencia interna o introspección? ¿Qué nos revela el lenguaje de la introspección? El lenguaje de introspección usa expresiones tales como "me siento alegre", "veo que mis imágenes son borrosas", "encuentro mis ideas muy iluminadoras de esta situación", "me encuentro agitado por la pasión del odio", "siento angustia", etc. ¿A qué se refieren estas expresiones? ¿Cómo ha surgido este modo de hablar y qué validez tiene?

Cuando digo que "tengo conciencia de un pensamiento", no me refiero a él como si dijera "veo un semáforo". La segunda expresión pertenece al lenguaje de observación, y ciertamente no tiene la misma referencia que el de introspec- 
ción. La observación se dirige a objetos públicos, mientras que la introspección se dirige a objetos privados, hechos mentales o cosas fenoménicas. Por ello hay que distinguir entre observación e introspección. Y aun el término "introspección" tiene diversos significados que conviene distinguir, a saber, inspección, introspección e introspección sistemática. Reinhardt Grossmann propone esta distinción y la ilustra con algunos ejemplos. Tomemos primero uno correspondiente a la inspección de cosas fenoménicas.

Se le muestra a alguien cierto objeto perceptible. Esta persona reconoce el objeto, ve que es redondo y de cierto matiz verde. Supongamos ahora que esa persona recibe la instrucción de describir no el objeto de su percepción, sino más bien las impresiones sensibles visuales que ella misma tiene en esa situación. Lo que se le pide que haga es, aproximadamente, que olvide que ante ella hay un cierto objeto perceptible y que se concentre en cambio en sus propias impresiones sensibles. Si esa persona entiende las instrucciones y ha sido ejercitada para cumplirlas, está haciendo una introspección de ciertas impresiones sensibles visuales. ${ }^{12}$

En este caso la atención de una persona, en virtud de una intención consciente, y como consecuencia de una tarea específica para la cual esa persona, aunque ordinariamente puede hacerla, ha sido ejercitada, se dirige no a objetos perceptibles, sino a lo que Grossmann ha llamado objetos fenoménicos.

Según este mismo autor, lo que se llama introspección ordinaria equivale a la inspección de objetos fenoménicos tal como ha sido descrita. Y pasa a ilustrar la introspección sistemática de procesos conscientes.

Supongamos que el sujeto de un experimento psicológico está ejercitado en buscar cierta palabra asociada siempre que se le presenta una particular palabra-estímulo. Percibir la palabraestímulo, buscar la palabra asociada apropiada y expresar ésta, constituye lo que puede llamarse el proceso consciente natural en esa situación. A continuación se instruye al sujeto para que describa lo que sucede en su mente en tanto está buscando la palabra asociada. O sea, debe informar acerca de sus cosas

12 R. Grossmann, La estructura de la mente. Barcelona. Labor, 1969. pp. 11-12. 
fenoménicas. Si las instrucciones son debidamente entendidas y el sujeto ha sido ejercitado para cumplirlas, estará dispuesto a hacer inspección de la aparición de la siguiente palabraestímulo. Sin embargo, como efecto de las instrucciones recibidas, se efectuará un cambio en los estados conscientes y pasará a hacer inspección de cosas fenoménicas. Al cabo de un breve momento el sujeto volverá de nuevo a la tarea de encontrar la palabra asociada. Y así sucesivamente. Ahora bien, este método tendrá o todos o algunos de los siguientes efectos en el proceso consciente natural de encontrar la palabra asociada: $a$ ) ciertos estados conscientes naturales no ocurrirán en absoluto; b) ocurrirán más tarde de lo que es normal, o c) no serán advertidos con la claridad normal. Esto muestra cómo la disposición a la inspección puede interferir con un proceso consciente natural; $y$ puesto que la introspección sistematica no puede llevarse a cabo sin aquella "disposición", se ve lo difícil que puede ser hacer sistemáticamente introspección de estados conscientes naturales. ${ }^{13}$

La introspección sistemática es difícil y llega a modificar las cosas fenoménicas sobre las que versa. Pero es factible. La introspección, pues, es una experiencia interna. Y sus enunciados pueden tomarse como enunciados empíricos; no ciertamente como enunciados empíricos en el sentido de "observacionales", según lo que se ha dicho de la observación exterior, sino como empíricos según esta experiencia interna o introspectiva, cuya realidad es innegable.

La confiabilidad de la introspección es un problema aparte y difícil. Pero, para nuestro propósito, basta decir que se ve garantizada por sus resultados. Nos descubre actos mentales (procesos o actividades), así como contenidos y objetos de estos actos.

Estos actos son expresados en lo que Peter Geach llama "reportes de actos mentales", que versan no sobre lo que los seres humanos dicen o hacen abiertamente, sino sobre lo que piensan, sienten, etc. ${ }^{14}$ Los reportes de actos mentales utilizan verbos psicológicos, como "ver". "esperar", "pensar", con lo

13 Ihid., pp. 14-15.

14 P. T. Geach. Mental Acts. Their Content and their Ohjects, London; Routledge and Kegan Paul. 1971 (reimpr.), p. 1. 
cual manifiestan su carácter psicológico. "Muchos de estos verbos psicológicos requieren un objeto gramatical - un nombre, una frase nominal, o una cláusula nominal - para completar su sentido. El héroe ve al cartero venir, oye su llamada, espera (tiene un súbito golpe de esperanza) con respecto a una carta de su amada, piensa que la carta que le envió a ella pudo haber sido abierta por su guardián, etc." $15 \mathrm{El}$ uso de tales expresiones es esencial para establecer el contenido de muchos actos mentales, por lo que les da el nombre de "expresiones de objeto". Pero prefiere evitar el uso del término "objeto" como algo que corresponda de manera demasiado realista a los actos mentales, para excluir problemas graves, como el que ocurre en el caso de objetos inexistentes. Por eso plantea los problemas "no en la forma ‘QQué clase de objetos tienen estos actos mentales?' sino más bien en la forma 'Tales y cuales expresiones de objeto se usan al describir estos actos mentales; ¿cuál es el papel lógico de estas expresiones?' ".16

Y el papel lógico de las expresiones de objeto que reportan actos mentales es doblemente peculiar: $i$ ) no se pueden reducir a un lenguaje fisicalista, y $i$ ) son indispensables si se quiere dar cuenta de la amplitud ontológica del mundo. Ambas peculiaridades tienen que ver con su status metodológico, explicativo-teorético.

El que no sean reductibles al lenguaje fisicalista los prepara como elementos teoréticos que se postulan, basados en la experiencia (interna), de manera consistente en el interior de una teoría. Si esta teoría admite entidades mentales, necesita expresiones que salvaguarden su peculiaridad. Hay una fuerte tentación a reducirlas, como en el caso del conductismo, a expresiones fisicalistas, dada la simplicidad que de ello resultaría. Pero la imposibilidad de reducirlas a lenguaje fisicalista $(o$, más propiamente, conductısta) se mantiene en base a ciertas consideraciones lingüísticas.

Por ejemplo, como lo muestra Wilfrid Sellars, al construir una teoría es de suma importancia metodológica la introducción del discurso semántico y del discurso teorético. Es

is Ihidem.

is Ihid.. p. 2. 
legítimo trabajar con un modelo que contenga elementos semánticos y teoréticos mentalistas para explicar los comportamientos. En este sentido,

aunque sería sumamente engañoso decir que los conceptos relativos al pensar son conceptos teoréticos, la condición de que gozan podría aclararse mediante un contraste entre el discurso teorético y el no teorético. Ahora estamos en situación de saber por qué sucede así. Pues una vez que nuestro antepasado Péręz [alguien que comenzó siendo conductista] ha puesto a punto la teoría de que el comportamiento verbal manifiesto es la expresión de los pensamientos, y ha enseñado a sus compatriotas a emplearla para interpretarse mutuamente el comportamiento, están todos a un paso de emplear este lenguaje en la autodescripción: así, cuando Juan, mirand o a Enrique, tenga elementos de juicio relativos a su comportamiento que justifiquen (en el lenguaje de la teoría) el uso de la oración "Enrique está pensando 'p' " (o "Enrique está pensando que p"), Enrique, empleando los mismos elementos de juicio, podrá decir, igualmente en el lenguaje de la teoría, "Estoy pensando 'p' "(o "Estoy pensando que p"); y ahora resulta - iera necesario que resultase? - que podrá enseñarse a Enrique a dar unas autodescripciones razonablemente fiables en el lenguaje de la teoría sin tener que observar su comportamiento manifiesto (cosa que Pérez podrá hacer, poco más o menos, alabando a Enrique cuando emita locuciones de la forma "Estoy pensando que p" en caso de que los elementos de juicio aludidos no apoyen este último enunciado). [Ellos], pues, empiezan a hablar del privilegiado acceso que tiene cada uno de nosotros a sus propios pensamientos: lo que empezó siendo un lenguaje dotado de un uso puramente teorético, ha llegado a tener un papel informador. ${ }^{17}$

Hay en todo ello un carácter intersubjetivo, pues se comparten los contenidos mentales mediante las expresiones, y su carácter informativo descansa precisamente en que son intersubjetivos (es decir, aunque son privados, no son meramente privados, se pueden comunicar).

Las expresiones mentalistas son indispensables si se

17 W. Sellars. "El empirismo y la filosofía de lo mental", en su obra Ciencia. percepcion y realidad, Madrid, Tecnos, 1971, p. 202. 
quiere dar cuenta de la realidad. Evidentemente, esto resulta de haber aceptado entidades mentales. Roderick Chisholm formula la tesis de la siguiente manera:

Digamos i) que no necesitamos usar lenguaje intencional cuando describimos fenómenos no-psicológicos o "físicos"; podemos expresar todo lo que sabemos, o creemos, sobre tales fenómenos en un lenguaje que no es intencional. Y digamos ii) que, cuándo deseamos describir ciertos fenómenos psicológicos -en particular, cuando deseamos describir el pensar, el creer, el percibir, el ver, el conocer, el querer, el esperar y el agradar - o bien $a$ ) debemos usar un lenguaje que es intencional o bien $b$ ) debemos usar un vocabulario que no necesitamos usar cuando describimos fenómenos no-psicológicos o "físicos". 18

La prueba que aduce Chisholm está basada en la circularidad en que incurre la postura no-intencionalista, por ejemplo, el conductismo. Tratemos de explicar las creencias de una persona. Podemos hacerlo en términos de lenguaje, ya sea aludiendo a su uso actual del lenguaje, o a sus disposiciones para usar el lenguaje en determinadas maneras. Pero no podemos describir su uso del lenguaje o sus disposiciones para usarlo de esas maneras, a menos que hagamos referencia a lo que cree, conoce o percibe, todo lo cual es intencional. ${ }^{19}$ Por ello, siempre será necesario el lenguaje intencional para dar cuenta de lo que sucede en el hombre. Ahora bien, las expresiones intencionales pertenecen al lenguaje mentalista, y éste tiene que acabar interpretándose como referido a entidades mentales, por más que se diga que el lenguaje mentalista es sólo un modo de hablar que no implica la existencia de entidades mentales. ${ }^{20}$ Pero la razón para postular entidades mentales (además de la experiencia interior) es que las expresiones intencionales no tendrían las características sintácticas y

18. R. Chisholm. "Sentences about Believing", en A. Marras (ed.), Intentionalit!. Mind and Language, Urbana. Chicago and London. University of Illinois Press, 1972. p. 35 .

${ }^{14}$ Cfr. Ihid., pp. 44-46.

20 Cfr. W. Quine, "On Mental Entities", en su obra The Wa!s of Paradox, New York: Random House, 1966, pp. 213-214. 
semánticas que tienen si no existieran los episodios mentales que les dan origen. ${ }^{21} \mathrm{Y}$ así, no podemos desechar el lenguaje sobre la conciencia como irreal o engañoso. Lo cual nos indica que la conciencia "está ahí".

21 Cfr. A. Kenny, "To Mind via Syntax", en The Nature of Mind, The Gifford Lectures 1971, 72. Edimburgh: University Press. 1972. 